\title{
A percepção dos estudantes no projeto pedagógico do Curso de Relações Públicas da UEL
}

\section{Students' perception of the pedagogical project of the Public Relations Course at UEL}

\section{Percepción de los estudiantes en el proyecto pedagógico del Curso de Relaciones Públicas de UEL}

\section{Maristela Romagnole de Araujo Jurkevicz}

- Doutora em Ciências da Educação pela Universidade de Trás-os-Montes e Alto Douro, Portugal

- Mestre em Educação pela Universidade Estadual de Londrina (UEL)

- Graduada em Relações Públicas pela UEL

- Especialista em Metodologia do Ensino Superior pela UEL

- Pesquisadora e professora adjunta da UEL

- E-mail: maristela.j@hotmail.com

\section{Marta Terezinha Motta Campos Martins}

- Doutora e mestre em Ciências da Comunicação pela Escola de Comunicações e Artes da Universidade de São Paulo (ECA-USP)

- Graduada em Comunicação Social pela Universidade Estadual de Londrina (UEL)

- Especialização em Relações Públicas Empresariais pela UEL

- Pesquisadora e professora adjunta da UEL

- E-mail: mmartins@uel.br

(9) Gabriel Henrique Arruda

- Graduando de Relações Públicas na Universidade Estadual de Londrina (UEL)

- Bolsista de iniciação científica do projeto de pesquisa Criação e análise de processos avaliativos, do Curso de Relações Públicas da UEL

- $\quad$ E-mail: gabriel.h.arruda@uel.br 


\title{
Resumo
}

Avaliar o currículo de um curso superior implica imergir em debates, escolhas, decisões tomadas na sua construção, para projetar caminhos consistentes que resguardem uma formação atualizada, crítica e competente. Este artigo apresenta os temas e as reflexões surgidos de uma pesquisa sobre a visão dos estudantes do Curso de Relações Públicas da Universidade Estadual de Londrina (UEL) com relação ao projeto pedagógico integralmente implantado em 2019. Os resultados englobam formação profissional, matriz curricular, atuação de professores, e as Diretrizes Curriculares Nacionais.

PALAVRAS-CHAVE: GRADUAÇÃO EM RELAÇÕES PÚBLICAS • PROJETO PEDAGÓGICO • AVALIAÇÃO • UEL.

\begin{abstract}
Evaluate the curriculum of a higher education course requires an immersion in debates, choices, decisions made in its assemble, in order to project consistent paths that result in updated, critical and competent education. This article presents the themes and reflections arised from a research on the view of students in the Public Relations Course at the State University of Londrina (UEL) in regarding to the pedagogical project implemented completely in 2019. The results include professional education, curriculum matrix, performance of teachers, and the National Curriculum Guidelines.
\end{abstract}

KEYWORDS: GRADUATION IN PUBLIC RELATIONS • PEDAGOGICAL PROJECT • EVALUATION • UEL.

\section{Resumen}

Evaluar el plan de estudios de un curso de educación superior implica sumergirse en debates, elecciones, decisiones tomadas en su construcción, para diseñar caminos consistentes que salvaguarden la capacitación actualizada, crítica y competente. Este artículo presenta los temas y las reflexiones que surgen de una investigación sobre la opinión de los estudiantes en el Curso de Relaciones Públicas de la Universidad Estadual de Londrina (UEL) en relación con el proyecto pedagógico implementado en su totalidad en 2019. Los resultados incluyen capacitación profesional, matriz curricular, desempeño del profesorado y las Directrices Curriculares Nacionales.

PALABRAS CLAVE: GRADUACIÓN EN RELACIONES PÚBLICAS • PROYECTO PEDAGÓGICO • EVALUACIÓN • UEL. 
$\mathrm{O}$ Curso de Relações Públicas da Universidade Estadual de Londrina (UEL) foi criado como habilitação da comunicação social mediante a Resolução no. 202, de 15 de dezembro de 1973, e implantado em 01 de agosto de $1974^{1}$. Nessa mesma década, conforme ressalta Margarida Kunsch (2002), ocorreu o surgimento de novos cursos no país, paralelamente à acomodação da categoria, proveniente da regulamentação da profissão. 0 Curso de Relações Públicas da UEL foi reconhecido pelo Decreto Federal no. 83.656, de 28.06.79, com a permissão para conferir, aos egressos, grau de bacharel em comunicação social.

Encontra-se atualmente em vigor o projeto pedagógico do curso (PPC), orientado de acordo com a Resolução no 2, de 27 de setembro de 2013 que estabeleceu Diretrizes Curriculares Nacionais para o Curso de Graduação em Relações Públicas. O PPC de relações públicas da UEL foi estabelecido e aprovado, pela Resolução no 005/2016 do Conselho de Ensino, Pesquisa e Extensão/Conselho de Administração (Cepe/CA), implantado em 2016, e consolidado integralmente no ano 2019, quando cumpriu o conjunto de atividades contidas na grade curricular proposta. 0 curso é ofertado em dois turnos (matutino e noturno), com quatro anos de duração, em regime seriado semestral, e funciona em sistema semipresencial.

\section{AVALIAÇÃO DO PROJETO PEDAGÓGICO DO CURSO}

Um projeto pedagógico de curso evidentemente requer avaliação periódica, de modo a permitir acompanhar como evolui o desenho do perfil profissional que os professores deverão adotar como norte para seu desempenho acadêmico. O PPC de relações públicas da UEL é perfilhado como componente de reflexão que abre possibilidades para se criarem novas alternativas e gerar o compromisso com a construção de um ensino efetivo, cada vez mais democrático e alinhado a seu tempo.

A avaliação foi desenvolvida por uma equipe de pesquisadores docentes do Curso de Relações Públicas da UEL pertencentes ao núcleo docente estruturante (NDE) e por estudantes de iniciação científica, que definiram, como objetivo geral, desenvolver instrumentos avaliativos formais do PPC em vigor, para aferir o potencial de garantir uma formação ajustada ao seu propósito. Os objetivos específicos definidos foram: a) criar e analisar de instrumentos avaliativos; b) orientar o grupo de docentes para alcançar as metas estabelecidas no PPC e tornar-se agente facilitador no sentido de ampliar a reputação já conquistada pelo curso da UEL ao longo de sua história, na qualidade tanto do ensino como da pesquisa institucionalizada.

Os participantes desse estudo localizaram e apreciaram um acervo de instrumentos avaliativos de cursos de graduação da UEL (jornalismo, música e enfermagem) e de outros cursos de graduação (administração, ciências contábeis) em outras instituições de ensino superior. A análise comparativa desses instrumentos foi descrita em outro artigo, contendo os detalhes de cada processo avaliativo, vantagens e desvantagens, metodologia e roteiro de análise, dentre outros aspectos. A investigação contribuiu na criação dos instrumentos avaliativos para o projeto pedagógico do Curso de Relações Públicas da UEL.

Cumprida a pesquisa documental, teve início a coleta de dados junto aos estudantes, e esse procedimento foi ancorado em metodologia qualiquantitativa. Para o enfoque quantitativo, foram elaborados dois questionários on-line, sendo um com questões para avaliação geral do curso e outro, para avaliação da série do aluno. Na fase qualitativa, a meta era o aprofundamento das informações, por meio de entrevistas em profundidade com os representantes de cada série, num total de oito entrevistas - quatro séries de dois turnos -, todas transcritas e analisadas qualitativamente. Após essa etapa, foram efetuadas análises cruzadas com apresentação de considerações e recomendações ao NDE do curso, para sugerir direcionamentos e ajustes necessários ao projeto pedagógico, visando manter a qualidade do ensino e da formação profissional pretendida.

1 Dados históricos extraídos e sintetizados do Projeto Pedagógico do Curso de Comunicação Social - habilitação em Relações Públicas da UEL (Universidade Estadual de Londrina, 2009). 
Em uma análise preliminar, os autores identificaram que os estudantes, a partir da terceira série, revelaram informações mais consistentes, exatamente pelo fato de terem vivenciado experiências que os conduziram a um amadurecimento na compreensão a respeito do significado de uma instituição de ensino superior, para além do interesse puramente voltado para o mercado de trabalho.

Os estudantes visualizaram o contato com a amplitude e a universalidade de conhecimentos recebidos, como algo que os torna agentes de um universo transformador. Pelas razões expostas, o teor das análises refere-se aos dados obtidos junto às turmas de terceiras e quartas séries do curso. Os temas e tópicos, descritos e pormenorizados, mostram o percurso de análise realizado pelo grupo de pesquisadores, bem como as considerações e propostas sugeridas para o curso.

\section{REVISÃO TEÓRICA}

\section{Avaliação institucional: conceituação}

A avaliação institucional é um levantamento de dados por meio do qual as instituições de ensino examinam o modo como as suas diretrizes curriculares estão sendo efetivadas e podem promover os ajustes necessários para a melhoria na qualidade do ensino e da formação oferecidos, aumentando a efetividade e qualidade do curso (NASCIMENTO et al., 2016). A avaliação institucional pode ocorrer de forma interna e externa. Na avaliação interna, alunos e professores exercem o papel de avaliadores, levantando informações, do seu ponto de vista, para repassar à equipe responsável pela coleta e análise dos dados. A avaliação externa é uma modalidade de apreciação realizada por órgãos e empresas especializadas.

Cabe ao Conselho Nacional de Educação (CNE), por meio da Câmara de Educação Superior, emitir resoluções que estabelecem diretrizes curriculares para os cursos de graduação. Essas diretrizes, orientam a equipe pedagógica no momento da criação do projeto pedagógico de curso e também ajudam a traçar o perfil do egresso que se pretende formar, assim como estabelecer as habilidades e competências compatíveis com o padrão estabelecido pelo curso (NASCIMENTO et al., 2016).

0 projeto pedagógico de curso, embora sirva como um instrumento para garantir que as diretrizes curriculares sejam seguidas, é por meio de avaliações institucionais, com levantamento de dados sobre a instituição, os docentes e os discentes que se pode averiguar e examinar minuciosamente a realidade do curso e da instituição (NASCIMENTO et al., 2016). 0 mesmo acontece com relação a saber se a implantação do projeto pedagógico está adequada aos propósitos que lhe deram origem.

A avaliação dos procedimentos e dos processos de ensino é uma ferramenta necessária para a compreensão dos problemas existentes, auxilia na identificação das causas desses problemas, ao mesmo tempo em que pode ajudar na implementação de medidas corretivas. A avaliação institucional tem como principal função orientar e corrigir os aspectos que foram investigados durante o levantamento de dados. É, portanto, indispensável realizá-la de tempos em tempos, para que o projeto pedagógico dos cursos de graduação continue garantindo uma educação de qualidade.

\section{0 projeto pedagógico de curso}

Os projetos pedagógicos não mais são vistos unicamente como exigência administrativa, e sim como um conjunto de documentos concebidos a partir de estudos e reflexões para atender às diretrizes curriculares nacionais, e orientar a 
instituição na superação dos desafios existentes. 0 projeto pedagógico de curso é o instrumento que norteia as práticas pedagógicas e a ação dos docentes e discentes; por isso, referir-se ao projeto pedagógico de um curso, é referir-se à sua identidade (SANCHES, 2007).

Segundo Maristela Jurkevicz (2010, p. 185), "após a sua constituição, o projeto pedagógico representa a essência da prática vivenciada por uma instituição, num determinado momento histórico". Marlene Grillo (2003, p. 32) menciona que o projeto "traduz a intenção do que se pretende realizar - projeções, inovações, mudanças, rupturas - e principalmente coragem e ousadia para propô-las." Alerta, contudo, o autor que, para que tenha significado, é essencial a participação dos professores na sua construção, e para isso devem ser oportunizados espaços para a adesão voluntária dos mesmos, em toda a sua elaboração. (GRILLO, 2003).

Diversas decisões devem ser tomadas para se construir o projeto pedagógico e constituir seus pressupostos teóricos, entre as quais: o tipo de ensino que se pretende realizar, tendo em vista a aprendizagem, os conteúdos, as metodologias e, também, a avaliação. Grillo (2003) acredita que todos esses elementos são igualmente relevantes, mas ressalta que a avaliação é que legitima a realimentação do processo.

0 projeto pedagógico deve ser elaborado com estratégias que orientem as ações disciplinares do curso, fundadas com base em teorias pedagógicas, que consideram a interação entre o curso e o contexto geral em que se insere, e estabeleçam, em sua concepção, um compromisso definido no coletivo (ZEM-MASCARENHAS; BERETTA, 2005). Segundo Sanches (2007, p. 53),

o projeto pedagógico possibilita a definição dos conteúdos, das metodologias, da situação existente e da desejada, das possibilidades e das necessidades. A instituição de educação, sendo o locus de execução e avaliação de seu projeto pedagógico, é, portanto, o espaço no qual emergem as dificuldades a serem enfrentadas. Quando essas dificuldades podem ser identificadas, proporcionam o surgimento de uma nova dimensão, a dimensão da ação intencional.

As alterações e correções no projeto pedagógico podem ser consideradas, como ações intencionais, porque os processos de avaliação institucional devem interferir nos projetos pedagógicos dos cursos à medida que forem identificando os problemas e as lacunas durante o levantamento de dados. Avaliar o desempenho dos cursos deve ser o ponto de partida para melhorias no projeto pedagógico e até mesmo nos próprios instrumentos de avaliação que já são utilizados. Delsi Davok (2006) destaca que a construção de sistemas de avaliação educacional com base em princípios, atributos e padrões tem obtido grande destaque nos debates sobre a avaliação da educação superior.

Na concepção de Cláudia Peixoto de Moura (2007, p. 61), "a busca pela qualidade do ensino em comunicação social necessita de muitos debates, com base no conhecimento existente e nas experiências dos professores e alunos envolvidos no processo de formação". Dessa forma, ao elaborar um sistema avaliativo, torna-se essencial dar voz a todos os atores do processo de ensino, gestores do curso, professores e alunos. Essa preocupação foi um dos fatores para a construção do novo instrumento avaliativo do Curso de Relações Públicas da UEL, com a criação de um espaço para interlocução de todos os sujeitos envolvidos no processo educativo.

Conforme José Augusto Pacheco e José Carlos Morgado (2002), a iniciativa de avaliar revela que os resultados poderão indicar novos nortes, para que decisões melhores sejam tomadas sobre o projeto curricular. Entende-se que a avaliação seja um processo dinâmico, que se dá em uma dimensão formadora e integradora das partes envolvidas, e abrange os participantes das bases que sustentam a formação de nível superior, a qual pressupõe uma conexão entre ensino, pesquisa e extensão. 


\section{METODOLOGIA}

Desde a implantação do novo currículo de relações públicas da UEL, o núcleo docente estruturante, em parceria com o colegiado de curso $^{2}$, vem acompanhando informalmente sua implantação, o desenvolvimento dos programas e das atividades previstas no PPC. A compreensão e implantação do processo avaliativo do curso, com a finalidade de apreciar a implantação do projeto pedagógico e seu impacto na formação profissional, buscou compreender, não apenas aspectos quantificáveis, mas também os essencialmente subjetivos relacionados à abordagem qualitativa. Foi, portanto, identificado que ambas as abordagens são essenciais no estudo, classificando-se então esta como uma pesquisa qualiquantitativa.

Na abordagem quantitativa, normalmente o fenômeno estudado já foi totalmente descrito e documentado por meio de pesquisas anteriores. As questões de pesquisa são direcionadas a explicar relações entre variáveis e permitem, ao pesquisador, extrapolar a partir dos dados, com o intuito de desenvolver uma explicação mais geral do fenômeno (GOLICIC; DAVIS; MCCARTHY, 2005).

Uma pesquisa qualitativa, por seu turno, é adequada quando o fenômeno de interesse é novo, dinâmico ou complexo, as variáveis relevantes não são facilmente identificadas e as teorias existentes não explicam o fenômeno (CRESWELL, 2010). Para o autor, a abordagem qualitativa provê, ao pesquisador, um conhecimento mais profundo de um fenômeno e produz um alto nível de detalhes. Nessa abordagem, o contexto é intrínseco ao objeto de estudo.

A pesquisa qualiquantitativa inclui a pesquisa qualitativa e a quantitativa, sendo também conhecida como mista, pois embora sejam diferentes, elas não se excluem. John W. Creswell (2010) afirma ser essa modalidade uma opção quando dados qualitativos e quantitativos são coletados e analisados para estudar um fenômeno num único trabalho. Lembra o autor que as tendências inerentes a um dos métodos, qualitativo ou quantitativo, podem neutralizar as tendências do outro método.

Mary E. Duffy (1987) aponta que a aplicação conjunta dos métodos traz certos benefícios, como: a possibilidade de controlar vieses (pela abordagem quantitativa) e a compreensão dos agentes envolvidos no fenômeno (pela abordagem qualitativa); identificação de variáveis específicas (pela abordagem quantitativa) e visão global do fenômeno (pela abordagem qualitativa); complementação de um conjunto de fatos e causas oriundos da abordagem quantitativa, com uma visão da natureza dinâmica da realidade; enriquecimento das constatações obtidas em condições controladas com dados obtidos no contexto natural.

A pesquisa quantitativa abordou todos os estudantes que estavam frequentando, da primeira à quarta série do curso, e teve a finalidade de apreciar como o projeto pedagógico foi percebido e assimilado pelos sujeitos. No instrumento de avaliação geral, foram investigados aspectos relacionados à coordenação do curso quanto ao diálogo e à disponibilidade, e o funcionamento da secretaria do departamento de comunicação. Outros itens investigados foram concernentes às bibliotecas central e setorial, estrutura física - laboratórios/hall do escritório de relações públicas/ praça do Centro de Educação, Comunicação e Artes (Ceca), avaliação do curso como um todo, projeto pedagógico e autoavaliação do aluno. No instrumento 2, denominado avaliação da série, foram apreciados os seguintes itens: organização de disciplinas/ equilíbrio; plataforma moodle; estrutura das salas de aula; avaliação de disciplinas da série.

A análise qualitativa apontou alguns aspectos subjetivos que foram identificados no relatório de gráficos e tabelas (confeccionados anteriormente) e levados à discussão com o público-alvo. A técnica utilizada foi a de entrevista em profundidade semiestruturada, com a gravação e, posteriormente, transcrição das falas e dos estímulos desenhados no encontro. A forma de contato com o público foi inspirada em auditorias de comunicação, selecionando líderes de turma para participar da construção da avaliação do curso.

20 Regimento Geral da UEL - Subseção IX, em seu art. 64. apresenta que os colegiados de cursos de graduação exercem a coordenação pedagógica dos cursos e são constituídos por docentes da área principal de conhecimento e da área básica e/ou complementar de conhecimento, estudantes e servidores. Os colegiados adotaram recentemente o núcleo docente estruturante (NDE), com a finalidade de assessorar o colegiado em discussões que envolvam o acompanhamento e avaliação do projeto pedagógico de curso. 


\section{RESULTADOS}

Na fase quantitativa, dos 160 alunos matriculados no Curso de Relações Públicas da UEL em 2019, 24 não estavam frequentando; portanto, teve-se 136 alunos que frequentavam efetivamente. Desse total, 16 estudantes não responderam aos questionários de avaliação, totalizando 119 respostas válidas. Estatisticamente, tem-se um índice de 99\% de confiabilidade (nível de confiança) e margem de erro de 3\%, utilizando a fórmula de cálculo amostral para populações não variáveis.

Foi selecionado o seguinte tópico do instrumento de avaliação geral do curso para ser apresentado neste relato: o projeto pedagógico do curso, no geral. Cada questão tinha uma resposta para ser assinalada pelo estudante numa escala variando de 1 a 6, com a correspondência semântica seguindo de "muito ruim" para o 1, "ruim" para o 2, "regular" para o 3, "bom" para o 4, "muito bom" para o 5 e "ótimo" para o 6. Esta escala apresenta autonomia semântica parcial, em que os respondentes são capazes de atribuir o conceito não apenas em termos de intensidade numérica, mas também de modo relativo às demais alternativas (CORBETTA, 2003, p.167, tradução nossa).

Da fase quantitativa, foram selecionados os seguintes tópicos para apresentar o relato neste estudo investigativo: a organização de disciplinas/equilíbrio das séries e a plataforma moodle, no ponto de vista dos alunos das duas últimas séries. A mesma escala de opinião foi utilizada. 0 quadro 1, a seguir, sintetiza os tópicos examinados e o que expressam nas duas abordagens.

\section{Quadro 1 - Síntese dos principais resultados para cada abordagem.}

\begin{tabular}{|c|c|c|}
\hline Item & Abordagem quantitativa & Abordagem qualitativa \\
\hline $\begin{array}{l}\text { Projeto pedagógico } \\
\text { do curso }\end{array}$ & $\begin{array}{l}\text { - Projeto pedagógico: 76,2\% de avaliação positiva ("bom”, “muito bom”, } \\
\text { "ótimo"); } \\
\text { • Curso: 76,3\% de avaliação positiva ("bom”, “muito bom”). }\end{array}$ & --- \\
\hline $\begin{array}{l}\text { Organização } \\
\text { de disciplinas / } \\
\text { equilíbrio }\end{array}$ & $\begin{array}{l}\text { - Organização: predominância do conceito "bom" (40\% para a 3a série e } \\
\text { 50\% para a } 4^{\text {ạ }} \text { série); } \\
\text { - Equilíbrio: predominância do conceito "bom" (33,3\% para a 3ª série e } \\
\text { 46,4\% para a 4ª série). }\end{array}$ & $\begin{array}{l}\text { - Desequilíbrio entre atividades teóricas e práticas; } \\
\text { - Períodos de sobrecarga; } \\
\text { - Falta a realidade do mercado de trabalho; } \\
\text { - Pouca prática na } 4^{a} \text { série. }\end{array}$ \\
\hline Plataforma moodle & $\begin{array}{l}\text { - Uso e acesso: } 33,3 \% \text { consideraram "ruim"; } \\
\text { - Pertinências das tarefas e atividades: } 71,4 \% \text { de avaliação negativa (ruim } \\
\text { e muito ruim). }\end{array}$ & $\begin{array}{l}\text { - Não apreciaram o EAD; } \\
\text { - Atividades pouco interessantes ou desafiadoras; } \\
\text { - Poderia ser mais bem planejada. }\end{array}$ \\
\hline
\end{tabular}

Fonte: Dados da pesquisa.

\section{Projeto pedagógico do curso}

Dos estudantes que responderam à pesquisa, 36,4\% consideraram que o projeto pedagógico vigente é "bom" e 32,2\% o consideraram "muito bom". Entendeu-se uma sinalização para algum ajuste no projeto; contudo, há necessidade de aprofundamento a respeito do tema específico em estudos posteriores. 0 gráfico 1 mostra, panoramicamente, a distribuição encontrada. 
Gráfico 1 - Projeto pedagógico vigente.

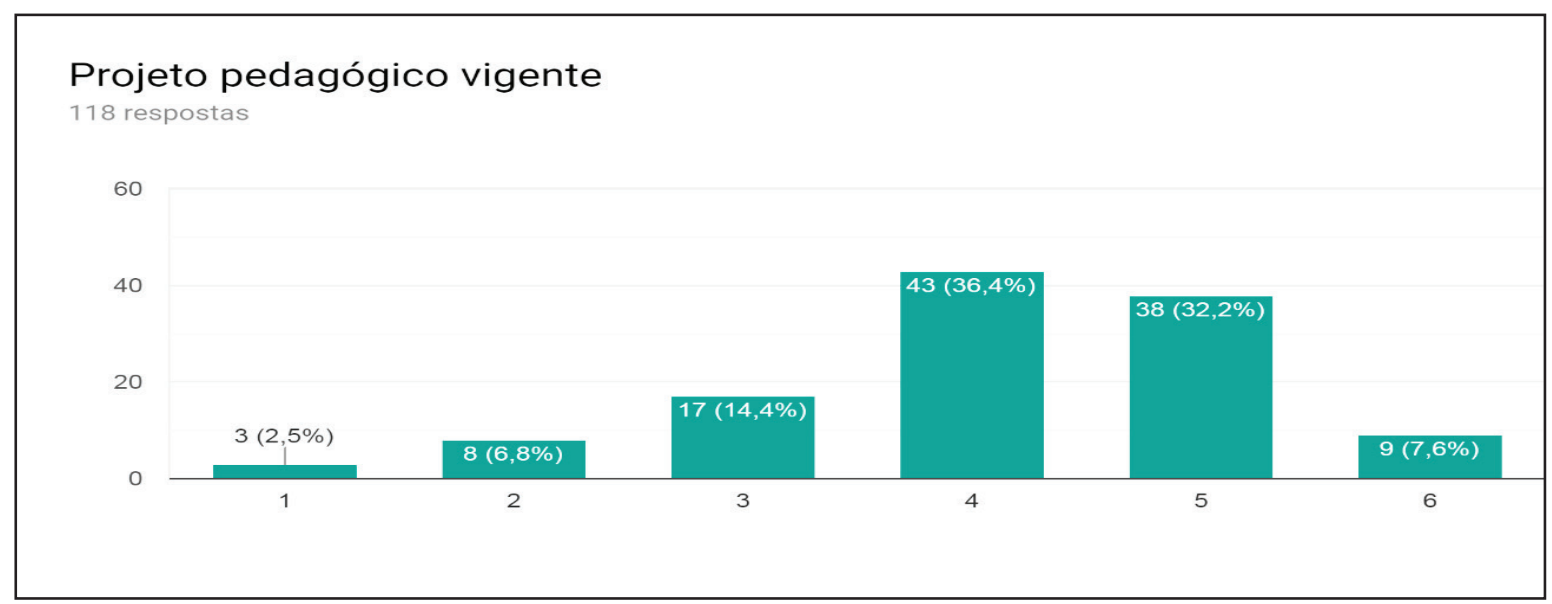

Fonte: Dados da pesquisa.

No geral, o Curso de Relações Públicas da UEL foi avaliado como "muito bom" por 47,5 \% dos respondentes e "bom", por $28,8 \%$. Os dados revelaram um nível de qualidade elevada praticada pelo curso.

\section{Organização de disciplinas/equilíbrio na abordagem quantitativa}

Para a 3ạ. série, as respostas tiveram uma maior concentração para a organização, vista como sendo "boa" por 40\% dos investigados, tendo ocorrido uma inclinação para o eixo direito das respostas, com 33,3\% respondendo "muito boa". Os dados revelaram que a 3‥ série satisfaz aos anseios dos estudantes quanto à organização, e se alinha ao PPC vigente. Quanto ao equilíbrio teoria/prática, os respondentes se opõem, visto que os dados se distribuem, quase igualmente, entre os dois polos do gráfico. Há contudo um terço $(33,3 \%)$ dos respondentes que assinalaram "bom" equilíbrio. Os dados conduzem a pensar em aprofundamento posterior, a respeito das variáveis que interferiram na oposição entre os polos.

A maior concentração de respostas para os estudantes da 4⿳a série, no aspecto organização, ficou no escore "bom" (50\%), seguido de 14,3\% no conceito "muito bom". Dos respondentes 32\% a classificaram entre os índices "regular" e "ruim". Apesar de a maioria dos estudantes considerar uma boa organização da série, deve-se dar uma atenção especial para apreciar quais disciplinas têm causado uma certa insatisfação. Quanto ao equilíbrio entre as atividades teóricas e práticas na série, o resultado manteve-se equivalente ao item acima, prevalecendo o conceito "bom" (46,4\%), seguido de "muito bom" $(14,3 \%)$.

\section{Plataforma moodle na abordagem quantitativa}

Para a 3a. série, 33,3\% dos investigados atribuiu valor equivalente a uso e acesso "ruim" da plataforma moodle. No entanto, as barras do gráfico expandiram-se para seu eixo direito, apresentando um total de $60 \%$ de respostas variando entre "regular" (20\%), "bom" (20\%), "muito bom" (16,7\%) e "ótimo" (3,3\%). A plataforma moodle apresentou-se, desse modo, como uma ferramenta que conta com a adesão dos estudantes, mas que necessita de melhorias em seu uso e acesso, conforme sinalizaram os respondentes.

Das respostas da 3a. série, 40\% recaíram sobre o conceito "ruim" no quesito tarefas e atividades da plataforma moodle. Ocorreu, também, de as barras do gráfico se expandirem para seu eixo direito, reforçando o entendimento de que a plataforma moodle é reconhecida como uma ferramenta viável que solicita melhorias em seu uso e acesso. 
Em um movimento ascendente em relação ao "uso e acesso" e à "pertinência das tarefas e atividades", apurou-se que $30 \%$ de respostas dadas pela 3a . série foram equivalentes à classificação "regular" para a plataforma moodle, no geral. Ocorreu inclinação para ambos os lados dos eixos do gráfico; portanto evidenciou-se a expectativa de que futuros estudos apurem, com mais detalhes, informações sobre o uso que está sendo feito da plataforma.

Estão previstas no PPC da 4⿳a . série, 90 horas de tecnologias da informação e comunicação. Ficou destacado, neste tópico avaliado pelos respondentes, o descontentamento com o uso da plataforma moodle em todos os aspectos, uso e acesso, pertinência das tarefas e atividades, bem como na avaliação geral. No tocante ao uso e acesso, despontou o conceito "muito ruim", com 42,9\%; com relação à pertinência das tarefas, os escores ficaram entre o "ruim" e o "muito ruim" (71,4\%) e 70\% dos respondentes assinalaram entre os índices "muito ruim", "regular" e "ruim" no quesito avaliação geral.

Sem dúvida, a plataforma moodle precisa ser rediscutida pelo núcleo docente estruturante do curso, sobre seu uso e acesso, bem como no que diz respeito à pertinência das tarefas e atividades. Infere-se, portanto, a partir dos dados apresentados, que a plataforma moodle necessita de ajustes e precisa ser reavaliada de forma criteriosa. Apesar de ser considerada uma ferramenta viável, requer cuidados para atingir toda a sua potencialidade.

$\mathrm{Na}$ fase qualitativa, foram selecionados os mesmos tópicos apresentados na fase quantitativa, a organização de disciplinas/equilíbrio das séries e a plataforma moodle, primeiramente na concepção dos estudantes das terceiras e quartas séries, para em seguida figurarem as discussões e considerações relacionadas a esses assuntos.

\section{Organização das disciplinas e equilíbrio entre atividades teóricas e práticas na abordagem qualitativa}

A turma da $3^{\underline{a}}$ série da noite considerou a $2^{a}$. série do curso mais empolgante do que a $3^{a}$. Exemplificaram com as disciplinas de pesquisa institucional e planejamento, na série atual, que estabeleceram trabalhos densos com datas de entrega muito próximas. Houve uma concentração de produção de escrita concomitante no primeiro semestre do ano letivo e as práticas ficaram concentradas no segundo semestre. Por razões como essas, a turma entendeu haver desequilíbrio entre atividades teóricas e práticas. Pode-se evidenciar que foi a questão de cronograma e agendamento de atividades de disciplinas distintas, em períodos comuns, a causa de sobrecarga para os estudantes.

0 representante da $4^{a}$. série do período matutino fez uma ponderação sobre o segundo semestre, em que a inclusão de novas disciplinas na grade curricular trouxe uma certa dificuldade para gerenciar as atividades. Comentou que, em conversas com os alunos de sua turma, foi sentida "a falta de uma realidade mais transparente em relação ao mercado. Não só ficar mostrando cases de sucesso, mas trazer as pessoas que falam sobre os problemas que elas enfrentam durante sua carreira, no mercado de trabalho".

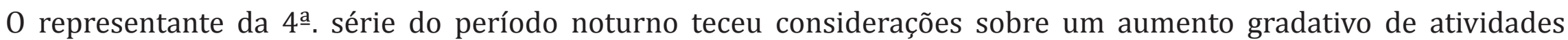
práticas na grade curricular. Explicou que, em sua percepção, com o passar dos anos, a cada série são acrescentadas mais ações práticas. Conforme os estudantes vão adquirindo mais conhecimento, o processo de elaboração e produção das estratégias comunicacionais fica mais facilitado. Entretanto, houve pouca prática na $4 \stackrel{a}{a}$. série, ressaltando-se principalmente atividades relacionadas a duas disciplinas - a de campos profissionais, com o desenvolvimento de artigos e a realização de seminários, e a organização de um evento na matéria de psicologia institucional.

\section{Plataforma moodle na abordagem qualitativa}

De acordo com representantes da $3^{a}$. série, algumas disciplinas trabalharam com postagem de atividades contando hora ou nota, e se tornaram pouco interessantes e desafiadoras. Por outro lado, houve professor que postou volume 
adequado de conteúdo e vídeos e, paralelamente, solicitou as atividades atraentes e sempre atuais. De modo geral, os estudantes da 3a . série não apreciaram o EAD, e não compreenderam o porquê da exigência de atividades virtuais, para além da falta de outra alternativa para cumprir carga horária de disciplinas semipresenciais. A percepção dos estudantes foi que o moodle é uma plataforma para realizar mais uma atividade, além das que já existiam nas aulas presenciais.

Ambos os representantes da $4^{a}$ série entenderam a necessidade de se ter a plataforma moodle, pois, caso contrário, o curso, para cumprir a totalidade da carga horária exigida pela Diretriz Curricular Nacional, precisaria ser integral, inviabilizando a turma do noturno. Ao mesmo tempo em que a ferramenta tem um grande potencial, muitas vezes não é utilizada da maneira adequada, tanto pelos professores, como pelos alunos. Portanto, de acordo com os dois representantes, a plataforma precisaria ser mais bem planejada, não utilizada somente para depositar material, mas para incluir vídeos, textos e materiais mais atrativos com a finalidade de complementar as aulas.

\section{DISCUSSÕES E CONCLUSÕES}

A organização das disciplinas foi avaliada como muito adequada pela 3a . série; satisfez aos anseios dos estudantes e se emparelhou ao projeto pedagógico de curso (PPC). Incluem-se nessa manifestação as perspectivas qualitativamente levantadas em entrevistas diretas com os representantes de turma dos turnos matutino e noturno. Novamente aqui o tópico organização das disciplinas foi avaliado, pela $4 \stackrel{a}{a}$. série, como satisfatório, atendendo às expectativas dos estudantes, tanto na fase quantitativa, como na qualitativa.

Quanto ao equilíbrio entre atividades teóricas e práticas, a pesquisa quantitativa realizada junto à 3a . série levantou dados que revelaram oposição entre os respondentes, apesar de a maioria $(33,3 \%)$ ter assinalado "bom" equilíbrio. Ao analisar as informações fornecidas na fase qualitativa, concluiu-se que a distribuição de atividades e tarefas, em períodos coincidentes entre disciplinas da 3ạ . série, merece um agendamento menos exaustivo para os estudantes, pois foi revelado stress elevado em períodos análogos. Apreendeu-se a possiblidade de elaborar um planejamento conjunto para a série, possivelmente resgatando, nas memórias do curso, experiências como a realização de reuniões de planejamento anual, coordenadas pelo colegiado, nas quais os planos de curso eram relatados por cada docente e o corpo todo analisava o que estava sendo proposto.

No que diz respeito ao equilíbrio entre atividades teóricas e práticas, a pesquisa quantitativa levantou dados apontando para uma maior concentração no escore "ótimo", seguido do "muito bom" pela 4⿳亠口冋. série. Apesar de os respondentes assinalarem como um equilíbrio satisfatório na fase qualitativa, foram identificadas manifestações de certo descontentamento, relacionadas à inclusão de novas disciplinas na grade curricular, no segundo semestre, dificultando o gerenciamento de atividades e, por outro lado, o desenvolvimento de poucas atividades práticas, somente solicitadas por duas matérias. Recomenda-se o planejamento conjunto de atividades a serem programadas no início do semestre, em reuniões gerais por séries e, por sugestão dos próprios alunos, a realização de palestras que mostrem a realidade do mercado de trabalho, as dificuldades, erros e acertos na trajetória profissional.

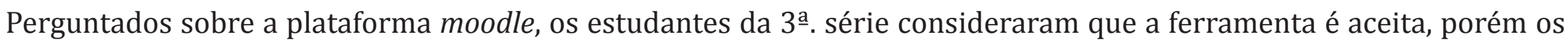
estudantes debitaram a ela a necessidade de avanços em seu uso e acesso. Embora a avaliação geral tenha revelado a pertinência e a facilidade que a plataforma proporciona, foi sinalizado que pode estar sendo mal empregada e impactando diretamente no melhor aproveitamento da ferramenta, nos processos de aprendizagem. Diante dos dados analisados recomenda-se, aos docentes reavaliar o modo como vêm empregando a plataforma, que revejam suas práticas e adotem formas inovadoras no desenvolvimento de atividades no moodle. Reafirma-se a expectativa por outros estudos que apurem mais informações sobre a plataforma, para focalizar, com segurança, as questões correspondentes. 
A plataforma moodle, no tocante ao uso e acesso, foi considerada muito ruim pela 4a - série, evoluindo para um nível maior de descontentamento quanto à pertinência das tarefas solicitadas. Seu potencial como ferramenta requer um maior direcionamento por parte de órgãos como o Laboratório de Tecnologia Educacional, cursos de capacitação aos professores visando melhorar a eficiência de utilização deste recurso, de maneira a promover a aprendizagem. Cabe também a cada docente buscar meios e estratégias para tornar as atividades mais significativas e atraentes para os estudantes.

\section{CONSIDERAÇÕES FINAIS}

A matriz curricular do Curso de Relações Públicas da UEL atende o conteúdo exigido pelas DCN, porém a carga horária imposta provoca impactos que fragilizam atividades que mereceriam mais ênfase no curso. Essa imposição de carga horária conflita com as características de um curso de turno parcial, ao abrir-se para alternativas possíveis, em detrimento do poder de optar pelo que seria o melhor.

Foi apurado que as condições físicas e estruturais de uma IES pública como a UEL, embora beire a precariedade, acaba compensada pelo desempenho de seu pessoal docente e técnico. Especialmente a rotatividade de professores vem provocando prejuízos imediatos e, por vezes, abordagens opostas ou distantes, entre docentes de uma mesma disciplina. Isso preocupa na formação de profissionais de relações públicas que compreendam a sociedade e se tornem aptos a apreciar o mundo atual como um ambiente complexo e desafiador. 0 curso requer abordagens inovadoras que qualifiquem os graduandos para projetar relacionamento com públicos em consonância com paradigmas de velocidade, competitividade e globalização.

\section{REFERÊNCIAS}

CRESWELL, John W. Projeto de Pesquisa: métodos qualitativo, quantitativo e misto. Porto Alegre, RS: Artmed, 2010.

CORBETTA, Piergiorgio. Social research: theory, methods and techniques. Londres: Sage Publications, 2003.

DAVOK, Delsi Fries. Modelo de meta-avaliação de processos de avaliação da qualidade de cursos de graduação. 2006.272 f. Tese (Doutorado em Engenharia de Produção) - Universidade Federal de Santa Catarina, Programa de Pós-Graduação em Engenharia de Produção, 2006.

DUFFY, Mary E. Methodological triangulation: a vehicle for merging quantitative and qualitative research methods. Journal of Nursing Scholarship, v. 19, n. 3, p. 130-133, 1987.

GOLICIC Susan L.; DAVIS, Donna F.; McCARTHY, Teresa M. A balanced approach to research in supply chain management. In: KOTZAB, Herbert et al. (eds.). Research methodologies in supply chain management. Heidelberg, Alemanha: PhysicaVerlag Heidelberg, 2005.

GRILLO, Marlene. Projeto político-pedagógico e prática avaliativa: uma relação necessária. In: ENRICONE, Délcia; GRILLO, Marlene (orgs.). Avaliação: uma discussão em aberto. 2 ed. Porto Alegre, RS: Edipucrs, 2003.

JURKEVICZ, Maristela Romagnole de Araújo. Avaliação da aprendizagem e formação do profissional de relações públicas: um estudo utilizando a metodologia da problematização. 2010. Dissertação (Mestrado em Educação) - Universidade Estadual de Londrina, Londrina, PR, 2010. 
KUNSCH, Margarida M. Krohling. História das relações públicas no Brasil: retrospectiva e aspectos relevantes. Idade Mídia, São Paulo, SP, a. I, n. 2, nov. 2002.

MOURA, Cláudia Peixoto de. Padrões de qualidade no ensino de comunicação no Brasil. In: KUNSCH, Margarida M. Krohling (org.). Ensino de comunicação: qualidade na formação acadêmico-profissional. São Paulo, SP: ECA-USP; Intercom, 2007.

NASCIMENTO, João Carlos H. Bernardes et al. Avaliação Institucional: aplicação discente em ciências contábeis. Future Journal, São Paulo, SP, v. 8, n. 2, ago. 2016.

PACHECO, José Augusto, MORGADO, José Carlos. Construção e avaliação do projecto curricular de escola. Porto, Portugal: Porto Editora, 2002.

SANCHES, Raquel Cristina Ferraroni. Avaliação institucional e projeto pedagógico: articulação imprescindível. 2007. Tese (Doutorado em Educação) - Faculdade de Filosofia e Ciências, Universidade Estadual Paulista, Marília, SP, 2007. Disponível em: <https://www.marilia.unesp.br/Home/Pos-graduacao/Educacao/Dissertacoes/sanches_rcf_dr_mar. pdf $>$. Acesso em: 23 set. 2019.

ZEM-MASCARENHAS, Silvia Helena; BERETTA, Maria Isabel Ruiz. Participando da construção de um projeto pedagógico da enfermagem. Revista da Escola de Enfermagem da USP, Universidade de São Paulo, v. 39, n. 4, 2005. Disponível em: <https://www.redalyc.org/articulo.oa?id=361033283010 >. Acesso em: 26 out. 2019.

Artigo recebido em 20.02.2020 e aprovado em 23.04.2020. 